\title{
A educação e o governamento dos corpos na atualidade: uma análise do "Movimento 21 dias por uma vida mais saudável"'
}

\section{Education and governance of bodies today: an analysis of the "Movimento 2 l dias por uma vida mais saudável"}

\author{
Leonardo Trápaga Abiba \\ (iD) https://orcid.org/0000-0001-9335-2141 \\ E-mail: leoabibळgmail.com \\ Ivan Marcelo Gomes ${ }^{a}$ \\ (i) http://orcid.org/0000-0002-0311-9651 \\ Email: ivanmgomesळhotmail.com \\ aUniversidade Federal do Espírito Santo. Centro de Educação \\ Física e Desportos. Vitória, ES, Brasil.
}

\section{Correspondência}

Leonardo Trápaga Abib

Av. Fernando Ferrari, 514, Campus Universitário Goiabeiras. Vitória,

ES, Brasil. CEP 29075910.

\section{Resumo}

Este trabalho teve como objetivo analisar os enunciados do programa de promoção da saúde "Movimento 21 dias por uma vida mais saudável" (M21), vinculado à Secretaria de Estado da Saúde do Espírito Santo. Para realizar tal proposta, investigamos, no período de setembro de 2015 a junho de 2017, os materiais disponíveis no site do programa, como notícias, textos, imagens, vídeos e peças publicitárias, dando ênfase aos elementos mais recorrentes. Nosso escopo de análise foi baseado no aporte foucaultiano, articulando os conceitos de biopolítica e poder pastoral com os conteúdos apresentados na página do M21. A partir das nossas leituras e análises, identificamos o uso corrente de enunciados econômicos e científicos acionados por dados estatísticos e falas de gestores e autoridades da área da saúde - nos materiais do M21, tendo como pano de fundo traços de uma racionalidade (neo)liberal, com o intuito de propagar conselhos sobre modos de viver a vida. O conteúdo do M21 adquire um tom moralista, que coloca nos sujeitos uma responsabilidade cada vez maior por seus estilos de vida, independentemente das condições em que vivem e a que são expostos, desconsiderando, assim, fatores estruturais que incidem sobre a saúde dessas pessoas.

Palavras-chave: Biopolítica; Poder Pastoral; Políticas de Saúde; Programas de Promoção da Saúde; Estilo de Vida.

1 Esse artigo está inserido no projeto “A educação do corpo e em saúde nos projetos, práticas e narrativas identitárias na região metropolitana de Vitória” (Edital Fapes nº 4/2015). Também foi financiado pela Coordenação de Aperfeiçoamento de Pessoal de Nível Superior (Capes). 
This paper aims at analyze the statements expressed in the program for health promotion entitled "Movimento 21 dias por uma vida mais saudável" (M21, from Portuguese "21 days for a healthier life movement"), linked to the Secretary of State for Health of Espírito (Brazil). For such, we investigated, from September 2015 to June 2017, the materials available on the program's website, such as news, texts, images, videos and advertising, focusing on recurrent elements. Our scope of analysis was based on Foucaultian framework, articulating the concepts of biopolitics and pastoral power with the content presented on M21's official webpage. Based on literature review and analyses, we identified the current use of economic and scientific statements - triggered by statistical data and statements from health managers and authorities - in the materials of M21, having traits of a (neo)liberal rationality as background, with the intention of propagating pieces of advice on ways of living life. The content of M21 carries a moralistic tone, which assigns individuals a growing responsibility for their lifestyles, regardless of the conditions in which they live and to which they are exposed, thus disregarding structural factors that affect those people's health.

Keywords: Biopolitics; Pastoral Power; Health Policies; Health Promotion Programs; Lifestyle.
Pois os senhores, ao que eu saiba, compuseram toda a sua lista de vantagens humanas fazendo uma média de valores estatísticos e de fórmulas da ciência econômica. De acordo com as suas conclusões, são elas o bemestar, a riqueza, a liberdade, a tranquilidade, e assim por diante.

Dostoiévski, 2016

A fala do personagem principal de Notas do subsolo, livro escrito pelo russo Fiódor Dostoiévski em meados do século XIX, nos apresenta, sob o tom irônico da obra, um traço da realidade daquele período: a entrada da vida nos cálculos estatísticos. No período entre os séculos XVIII e XIX, os modos de viver a vida começaram a ser traduzidos e pautados pelo emergente campo da ciência moderna, colocando a estatística e a demografia como ferramentas para o governo das populações por parte do setor industrial e estatal. Por isso, como acusa o personagem, a partir da produção das médias de valores estatísticos e das fórmulas econômicas, tentou-se conduzir os indivíduos e as populações para um determinado modelo normativo de viver a vida.

Do século XIX para o XXI, nota-se o interesse, ainda crescente, na discussão sobre os estilos de vida da população. Essa questão tem sido recorrente em debates nos campos acadêmico, científico, midiático, publicitário, da gestão pública, entre outros. Um dos tantos efeitos gerados por essa discussão tem se refletido em propostas de programas de promoção da saúde. Seja na esfera pública ou na privada, tem-se notado que uma parcela considerável desses programas vem focando na mudança do estilo de vida das pessoas como principal estratégia para promover qualidade de vida, prevenção de doenças, aumento da produtividade, diminuição de gastos com saúde etc. (Ávila, 2014; Ferreira Neto et al., 2009; Mázaro; Bernardes; Coêlho, 2011).

Cada vez mais acompanhamos a disseminação de enunciados a respeito dos benefícios e prejuízos decorrentes de nossas escolhas individuais, independente de outros fatores que escapam de nossa vontade. 0 incentivo ao governo de si e dos outros, segundo uma lógica baseada na ideia de que "basta querer mudar de costumes", emerge inserido em um 
tipo de controle e vigilância mais sutil e pragmático (Castiel; Moraes; Paula, 2016), tendo a vida - aliás, os modos de viver a vida -, como eixo central. Assim, no momento em que a vida se torna o campo de batalhas moderno, novas e velhas formas de governamento e educação dos corpos são ativadas conjuntamente.

De acordo com Nikolas Rose (2011), tal perspectiva de governo aponta para programas, propostas e políticas que têm incidindo sobre os corpos e a conduta dos indivíduos. $\mathrm{O}$ autor argumenta que parte das preocupações com o self estão ligadas à emergência de uma série de programas políticos e de técnicas que buscam "governar não através da sociedade, mas através das escolhas instruídas e informadas de cidadãos, famílias e comunidades ativas" (Rose, 2011, p. 36).

Diante de tal panorama, interessanos seguir as pistas deixadas pelos estudos sobre as estratégias biopolíticas ${ }^{2}$ contemporâneas no campo da promoção da saúde (Castiel; Moraes; Paula, 2016; Ferreira Neto et al., 2009; Furtado; Szapiro, 2012). Para isso, elegemos o programa Movimento 21 Dias por uma Vida Mais Saudável (M21), do Governo do Estado do Espírito Santo, como nosso objeto de estudo.

O objetivo deste trabalho foi analisar os enunciados do programa M21 a partir dos conteúdos presentes na sua página oficial, ${ }^{3}$ como desafios, imagens, vídeos, falas de gestores e notícias indexadas no site, com o intuito de compreender e refletir sobre as manifestações biopolíticas atuais e as formas contemporâneas de governamento e educação dos corpos. De uma forma geral, interessou investigar como esse tipo de política de promoção da saúde tenta incidir sobre os modos de vida dos sujeitos na atualidade.

\section{O Movimento 2l dias por uma vida mais saudável}

No Estado do Espírito Santo, há diversas cidades adotando programas vinculados à Política Nacional de Promoção da Saúde, seja implantando academias de ginástica em locais públicos, realizando oficinas e grupos dentro das Unidades Básicas de Saúde, seja aumentando o número de equipes do Núcleo de Apoio à Saúde da Família, entre outras iniciativas. $\mathrm{Na}$ esteira desses programas, o governo estadual do Espírito Santo, por meio da Secretaria de Estado da Saúde (Sesa), lançou no dia 16 de outubro de 2015 o Programa Vida Saudável (PVS), “cujo objetivo é incentivar a população a mudar seu estilo de vida em benefício da própria saúde, evitando diabetes, hipertensão, obesidade, problemas cardíacos e diversas outras enfermidades" (Rodrigues, 2015). Junto com o programa também foi lançado o M21, como primeira estratégia do PVS. Nas palavras do governo estadual,

Estudos mostram que 21 dias é o tempo ideal para que o organismo comece a se acostumar com uma nova atividade e passe a realizála automaticamente. Pois o Movimento 21 Dias vai ajudar o cidadão a começar uma mudança de hábitos de forma fácil e divertida. [...] A pessoa pode escolher mais de um desafio ao mesmo tempo e também pode convidar amigos, família e colegas de trabalho para fazer parte deste movimento, gerando assim uma disputa saudável. (Stutz, 2016)

A respeito dos desafios, eles estão divididos em três grupos diferentes: alimentação saudável, atividade física e convívio familiar. Cada desafio de um grupo apresenta uma descrição e algumas dicas para ajudar, instruir e ensinar estratégias para a pessoa praticar. Ao clicar no botão "começar", o site passa a acompanhar o processo de cada sujeito, que precisa marcar via site ou aplicativo de celular se conseguiu cumprir o desafio dia após dia.

As atividades propostas pelo M21 são bastante variadas. No grupo da alimentação saudável, por exemplo, constam desafios como diminuir açúcar, diminuir sal, consumir mais frutas, legumes e verduras, comer cinco cores ao dia, comer de 3 em 3 horas, entre outros. Já no grupo das atividades físicas são

\footnotetext{
20 conceito de biopolítica aparece na obra de Michel Foucault na década de 1970, sendo abordado nos cursos proferidos no Collège de France, Em defesa da sociedade (2005), Segurança, território, população (2008b) e Nascimento da biopolítica (2008a). Em suas genealogias, Foucault aponta que nos séculos XVIII e XIX emergem diferentes tecnologias de poder: por um lado, as disciplinas e a anatomopolítica do corpo humano, focada em exercer um poder sobre o corpo individual, até então tido como uma máquina; e por outro lado, uma biopolítica das populações, com ações centradas no corpo espécie, nos processos biológicos das pessoas - nascimento, mortalidade, saúde, duração da vida.

3 Disponível em: <http://www.movimento21dias.com.br>. Acesso em: 26 ago. 2019.
} 
sugeridos desafios como fazer pequenas pausas para alongamento durante o dia, pular corda por 20 minutos, andar de bicicleta por 30 minutos e espreguiçarse ao levantar. Por fim, no grupo do convívio familiar surgem desafios tais como reunir a família à mesa nas refeições, brincar ou jogar em família, criar projetos em grupo, promover ambiente harmonioso etc. Vale destacar que a ideia promovida pelo programa é de que as pessoas escolham um ou mais desses desafios e os pratiquem durante 21 dias seguidos.

No site do programa M21 é possível encontrar as listas com a apresentação e descrição dos desafios, o ranking de usuários cadastrados, recomendações, dados estatísticos, imagens, vídeos e notícias. Para participar, é necessário cadastrarse no site ou baixar o aplicativo de celular, pelo qual é possível receber notícias, aderir aos desafios e relatar se está realizando ou não as atividades escolhidas. O cadastro é gratuito, e até julho de 2017 existiam 30.281 pessoas cadastradas, 47.202 desafios assumidos e 152.432 medalhas $^{4}$ alcançadas pelos usuários. Segundo dados do site do M21, o desafio mais assumido pelos usuários até esse período foi caminhar ou correr 30 minutos por dia, enquanto o desafio mais concluído foi reduzir alimentos industrializados.

Ainda a respeito das plataformas de interação do M21: no site aparecem fotos das pessoas que se cadastraram, assim como seus nomes completos na página do ranking. Ao se cadastrar no programa, é necessário ler e aceitar o termo de participação no qual uma das questões é o livre uso de imagens, perfis em redes sociais, nomes para serem usados em campanhas, promoções, divulgação etc. 0 site do M21 sugere aos participantes do programa que utilizem a hashtag \#Movimento21dias nas redes sociais tais como Facebook, Twitter e Instagram, com o objetivo de visibilizar seus desafios assumidos e como os estão colocando em prática. O uso e a difusão da hashtag também funciona como uma forma de tentar disseminar mais o programa e seus conteúdos na mídia para que mais pessoas possam se inserir e se cadastrar nele.

\section{Trajetória metodológica}

Para realizar a análise dos enunciados presentes nas plataformas digitais do M21, optamos por partir da perspectiva foucaultiana de problematização, de crítica do presente, da interrogação sobre a nossa atualidade. Para Foucault (1988 apud Cardoso, 1995), a problematização, enquanto crítica, constituise num certo "ethos filosófico", uma atitude de relacionar-se com a realidade atual, uma maneira de pensar e de sentir, enfim, uma crítica permanente de nossa era. Nosso esforço aqui neste trabalho é problematizar as formas com que programas como o M21 buscam atuar sobre a constituição dos sujeitos, tentando conduzir seus modos de vida na nossa atualidade.

Ao assumir tal objetivo, passamos a acompanhar, ler e analisar os materiais e conteúdos presentes no site do M21, como textos, imagens, vídeos, peças publicitárias e notícias, no período de setembro de 2015 a junho de 2017. Todos os materiais puderam ser acessados a partir da homepage do projeto, na qual encontramos links específicos para cada um dos grupos (alimentação, atividade física, convívio familiar) e seus respectivos desafios, assim como para ler notícias, assistir a vídeos, fazer downloads de peças gráficas, acessar o ranking dos usuários cadastrados etc.

Os dados suscitados pelas plataformas digitais do M21 foram registrados em diários de navegação, que continham descrições daquilo que estava presente no site e no aplicativo do programa, como os tipos de informação que eram privilegiados; quais eram os interlocutores das mensagens e notícias; quais foram as referências citadas; como eram as figuras e símbolos da página na web; quais desafios eram mais escolhidos pelos usuários, entre outros elementos. Durante a fase de análise e interpretação dos dados produzidos, buscou-se trabalhar analiticamente com algumas das ferramentas conceituais propostas por Foucault, na perspectiva de "tornar visível o que precisamente é visível - ou seja, fazer aparecer o que está tão próximo, tão imediato, o

4 Ao completar os 21 dias, o usuário cadastrado recebe o número de medalhas virtuais correspondentes ao desafio concluído. 
que está tão intimamente ligado a nós mesmos” (Foucault, 2006, p. 44).

Durante essa fase de levantamento de dados, consideramos as informações e características mais constantes e recorrentes no site, de modo que optamos pela construção de dois eixos principais de análise, tendo como pano de fundo as discussões foucaultianas sobre as relações entre poder, corpo e "governamentalidade". No primeiro eixo, partimos da hipótese conceitual de que o M21 estaria inserido no bojo dos dispositivos biopolíticos contemporâneos pautados pela racionalidade liberal; no segundo eixo, discutimos a relação entre o conceito de poder pastoral com as estratégias de intervenção instigadas pelo M21 por meio do investimento em uma política orientada para a condução de condutas individuais, visando a mudança de hábitos nas áreas da alimentação, atividade física e convívio familiar.

Ambos os eixos articulam-se de maneira complementar, de modo que o poder pastoral se mostra como um adendo às estratégias biopolíticas para a produção de sujeitos governáveis em um contexto de liberdades controladas em nome da economia, segurança e produtividade.

\section{O M2ı enquanto dispositivo biopolítico}

Nesta etapa de análise, problematizamos as informações textuais presentes no site do M21, tais como os estudos e dados estatísticos usados como meio de incentivar os sujeitos a se engajar na realização dos desafios colocados pelo programa. Diante dessas informações, passamos a notar como essas mensagens se articulam com uma política que tem como cerne não somente a vida das pessoas, mas também os modos de viver essa vida. Para cumprir tal política, são utilizadas diferentes justificativas, tanto biológicas quanto econômicas e estatísticas. Com isso, passamos a compreender o M21 enquanto

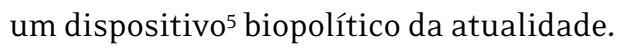

Autores como Castro (2007, 2011), Rose (2013), Rabinow e Rose (2006) pautam a necessidade de se analisar a biopolítica de uma forma mais contemporânea, tendo em vista que os estudos de Foucault se dão até a metade do século XX. Para esses autores, é preciso investigar como as estratégias biopolíticas têm se configurado na atualidade em suas relações com as ciências, a educação, a saúde, as formas de governo da população e de suas condutas.

Para Rabinow e Rose (2006), os conceitos foucaultianos de biopoder e biopolítica mantêm certas unidades analíticas, permitindo a construção de um plano de atualidade pautado por pelo menos três elementos: os discursos de verdade a respeito do caráter vital dos seres humanos e um conjunto de autoridades consideradas como competentes para proferir tais discursos; estratégias de intervenção sobre grupos/coletividades biossociais emergentes; e modos de subjetivação, nos quais sujeitos são levados a atuar sobre si mesmos, "sob certas formas de autoridade em relação a discursos de verdade, por meio de práticas do self, em nome de sua própria vida ou saúde, de sua família ou de alguma outra coletividade" (Rabinow; Rose, 2006, p. 29).

Acerca desses três elementos, acreditamos ser pertinente a leitura dos enunciados e das ideias disseminadas pelo M21 em suas plataformas digitais e sua relação com o conceito de biopolítica na atualidade. Ao ler as reportagens e textos indicados pelo M21 na seção “Notícias”, encontramos falas de gestores da área da saúde no estado do Espírito Santo que nos deram pistas para analisar como o programa se articula com a ideia de dispositivo biopolítico na contemporaneidade.

Durante evento de lançamento do PVS e do M21, uma das gestoras responsáveis pelo Programa aponta que a forma como as pessoas vivem impactam em suas condições de saúde e doença e, para que elas possam ter melhores hábitos, é necessário que se invista em ações preventivas (Rodrigues, 2015). No mesmo evento, a presidenta do Conselho de Secretários Municipais de Saúde do Espírito Santo completa o pensamento anterior afirmando que "a saúde é uma tarefa de todos. Do Estado, da família e das pessoas. As pessoas se expõem aos riscos por causa dos hábitos de vida e deixam para

5 Para Foucault (200o, p. 244), dispositivo seria "um conjunto decididamente heterogêneo que engloba discursos, instituições, organizações arquitetônicas, decisões regulamentares, leis, medidas administrativas, enunciados científicos, proposições filosóficas, morais, filantrópicas. Em suma, o dito e o não dito são os elementos do dispositivo. O dispositivo é a rede que se pode tecer entre estes elementos". 
o Estado a tarefa de cuidar" (Rodrigues, 2015). Já o Secretário Estadual de Saúde, durante outro evento de divulgação do M21, comentou que "é muito importante que as pessoas assumam a responsabilidade por sua saúde. Logicamente que o Estado continuará a fazer a sua parte. No entanto, queremos que as pessoas tenham uma melhor qualidade de vida" (Muniz, 2016).

Nas falas dos gestores, podemos identificar alguns elementos norteadores do PVS e, consequentemente, do M21, como o ideário da promoção da saúde, a articulação entre diferentes instâncias administrativas, a prevenção de doenças, a noção de risco, a responsabilização das pessoas com seus hábitos de vida, o financiamento e os gastos com saúde, o interesse na vitalidade da força de trabalho.

Com a emergência da biopolítica, o interesse político sobre a vida e as condutas das pessoas passa marcadamente pela relação econômica. A preocupação dos gestores com os gastos em saúde é uma das justificativas para defender a existência de um programa como o M21, que tem como premissa induzir e instigar os sujeitos a se autocuidar, a se autorresponsabilizar pela prevenção de doenças cujos tratamentos possam ser custosos para o setor público e privado. Essa forma de governo tem relação estreita com a racionalidade política do liberalismo, na qual, segundo Foucault (2008a), não há uma valorização das liberdades individuais, e sim uma proteção da economia de mercado, valendo-se de estratégias para ampliar o governo das populações, porém, governando o mínimo possível. Podemos ver esse tipo de pensamento na fala do Presidente da Associação dos Municípios do Estado do Espírito Santo (apud Rodrigues, 2015):

Estamos vendo muitos prefeitos tendo problemas porque a capacidade de resolutividade dos municípios está cada vez menor. Tem que ter contrapartida da população para otimizarmos os recursos e fazermos uma saúde mais resolutiva.

Em consonância com esse argumento, trazemos aqui a fala de uma das gestoras da equipe responsável pelo M21 durante a apresentação do programa para setores do comércio e indústria:
Quando as empresas promovem ações que estimulam seus colaboradores a terem hábitos saudáveis, o resultado é menos adoecimento, mais produtividade e menos faltas ao trabalho. É positivo para ambos os lados. (Membros..., 2015)

Em tempos marcados pela ampliação dos dispositivos biopolíticos e pela racionalidade neoliberal (Bazzicalupo, 2013; Castiel; Moraes; Paula, 2016; Passetti, 2013), as ações advindas e propostas pelo Estado em articulação com o setor privado têm tido uma tendência a diminuir os investimentos públicos em áreas como educação, saúde e segurança, além da construção da narrativa do "rombo" da seguridade social para justificar cortes e suspensão de direitos (Bauman, 2005; Castel, 2004). Para isso, a participação e o autocontrole dos sujeitos são uma das formas de o Estado investir menos no sentido econômico e mais no âmbito das condutas. Dessa forma, de acordo com Furtado e Szapiro (2012, p. 820), pode-se considerar que o investimento em políticas que visem o controle dos corpos individuais, sob o discurso do cuidado com a saúde da população, "funciona hoje como um poderoso dispositivo de regulação do indivíduo, do espaço social, e de fim do Estado de Proteção Social”.

Diante de tal cenário, criam-se diferentes narrativas para construir um imaginário social capaz de mobilizar os sujeitos a se cuidar mais e a demandar menos dos campos estatais e privados. De acordo com os argumentos apresentados acima pelos gestores da saúde do estado do Espírito Santo, encontramos o incentivo ao uso "racional" da máquina pública como uma tarefa de todos, e não somente do governo do estado; outra narrativa é a de que, ao seguir os desafios rumo a um estilo de vida saudável, as pessoas irão adoecer menos e, assim, produzirão mais e por mais tempo, o que é de interesse também dos setores privados da economia.

Para além das justificativas econômicas presentes nas falas dos gestores, outro elemento da biopolítica na atualidade diz respeito aos discursos de verdade sobre a vitalidade humana e o respectivo conjunto de autoridades julgadas como capazes de reproduzir esses discursos. No site do M21, é possível encontrar na seção "Sobre o Movimento" uma área intitulada "Alguns dados que chamam atenção". Nessa área são apresentados aos usuários dados e 
estatísticas (com fontes referenciadas) sobre saúde, doença, alimentação e atividade física. Por exemplo:

Doenças crônicas nãotransmissíveis são responsáveis por até $63 \%$ das mortes no mundo e $72 \%$ no Brasil, e um terço dos óbitos ocorre em pessoas com menos de 6o anos. (Ministério da Saúde, 2014 apud Sobre..., 2015)

O excesso de sal na alimentação está ligado ao aumento no risco de doenças como hipertensão, doenças cardiovasculares, doenças renais e câncer no estômago. (Ministério da Saúde, 2014 apud Sobre..., 2015)

Diminuir o consumo de açúcar reduz o risco de sobrepeso, obesidade e cárie dentária e até alguns tipos de câncer. (OMS, 2015 apud Sobre..., 2015)

$13 \%$ das mortes no Brasil têm como origem o sedentarismo. (Revista médica Lancet, 2013 apud Sobre..., 2015)

Primeiro, a respeito do tipo de enunciado e de dado científico utilizado, nota-se a predileção por textos curtos e com informações pautadas por estatísticas que buscam reforçar o ideário do M21, tendo a noção de risco como algo em comum entre as mensagens explicitadas. Segundo, esse caráter científico contido nos trechos supracitados também é utilizado na apresentação e justificativa do M21 e do porquê de se ter que fazer uma rotina prevista para 21 dias. Em notícia no site do programa, encontrase a seguinte informação: "estudos mostram que 21 dias é o tempo ideal para que o organismo comece a se acostumar com uma nova atividade e passe a realizála automaticamente" (Governo..., 2016). Contudo, de maneira contraditória aos enunciados acima, não são citadas as bases científicas nas quais o programa se fundamentou para construir sua proposta. Somente em um dos comerciais de divulgação do programa (que se encontra disponível na seção "Vídeos e Downloads”) é possível encontrar pequenos recortes de títulos de matérias veiculadas por outros sites (também não referenciados) que falam a respeito do que seria "a técnica (ou a teoria) do 21 dias". Ao pausar o vídeo no momento em que surgem tais recortes e realizar a leitura dos títulos e subtítulos dessas matérias, nota-se a presença de distintos discursos neurocientíficos, comportamentalistas e até mesmo da área da autoajuda - que buscam legitimar a "teoria dos 21 dias" propagada pelo programa.

Portanto, se os fatores econômicos são apresentados pelos gestores, os fatores físicos e orgânicos são atrelados a um determinado tipo de discurso científico, baseado nos dados demográficos e nas estatísticas, nos organismos e revistas internacionais, em núcleos de pesquisa e na figura do médico, sujeito protagonista que apresenta o comercial do M21 na televisão e que aparece nas imagens do site do programa. Munir os sujeitos com informações científicas é uma das bases para difusão das estratégias que vêm privilegiando a prescrição comportamental individual em detrimento de ações que visem transformações de nível estrutural e coletivo. Tais estratégias têm reverberado em

um conjunto de prescrições acerca da adoção de estilos de vida tidos como mais saudáveis. É preciso dizer que a panaceia a qual nos referimos anteriormente está articulada a uma biopolítica que visa regular a maneira como os indivíduos vivem a sua própria vida. (Bilibio; Damico, 2011, p. 96)

O uso dessas informações científicas tem contribuído para a promoção de um conjunto de políticas da vida que se expressam por meio de uma articulação entre o campo dos enunciados verídicos - aqueles com base na ciência - e o campo de práticas de governamentalidade ${ }^{7}$ para o governo das condutas individuais, no caso as condutas de cada indivíduo e aquelas em que cada um passa a exigir dos outros (Costa, 2016). Assim como outros espaços que postulam em nome da promoção da saúde, como sites, jornais e blogs, (Fraga, 2005; Gomes, 2008;

6 Disponível em: <http://bit.ly/2Nv6irT>. Acesso em: 26 ago. 2019.

7 Foucault chamou de "governamentalidade" o complexo de noções, cálculos, estratégias e táticas por meio do qual diversas autoridades (políticas, militares, econômicas, teológicas, médicas) procuraram/procuram agir sobre as vidas e condutas de todo e cada indivíduo, de forma a evitar males e atingir estados desejáveis de saúde, riqueza etc. (Foucault, 2ooo). 
Pich, 2016), o M21 utiliza desses conselhos científicos com a intenção de mostrar para os usuários como a adoção desse estilo de vida difundido nos enunciados do site é necessário à prevenção de riscos e à promoção de certo "bem=viver". Para sustentar essa necessidade, é mobilizada uma série de autoridades (Ministério da Saúde, Organização Mundial da Saúde, núcleos de pesquisa) tidas como especialistas na saúde, visando tornar esses dados mais racionais e pertinentes. Entretanto, é válido retomar que os conselhos científicos advindos de tais instituições, mobilizadas enquanto autoridades legítimas para falar sobre saúde, foram pouco utilizados para justificar a tese específica dos “21 dias”, sendo mais divulgados por conta das estatísticas sobre comportamentos que estariam dentro dos fatores de risco para doenças crônicas não transmissíveis, de modo a tentar convencer, de forma mais assertiva, as pessoas a reverem seus hábitos pessoais mediante a administração dos riscos - o que nos parece ser a pauta central da proposta apresentada pela Sesa.

Ademais, outros tipos de dados estatísticos são utilizados para alertar a população capixaba e tentar dar maior sustentação aos argumentos para as pessoas aderirem ao estilo de vida "padrão M21":

Dados recentes do Instituto Brasileiro de Geografia e Estatística (IBGE) mostram que 52,4\% dos capixabas estão acima do peso ideal e estão sujeitos a problemas como diabetes e hipertensão arterial. O problema atinge homens e mulheres praticamente na mesma proporção.

O acúmulo de gordura no abdômen, outro perigo para a saúde mesmo daqueles que estão dentro do peso adequado, atinge $43,5 \%$ dos capixabas. (Governo..., 2016)

Ademais, outra característica dos dispositivos biopolíticos que pudemos mapear em nossas análises nos enunciados do site do M21 é a difusão e o uso do conhecimento biológico e corporal (como mostram os dados acima referenciados) ante os indivíduos sobre os quais se quer atuar. A partir da análise das populações por meio desses cálculos, as estratégias biopolíticas, ancoradas dentro de uma racionalidade (neo)liberal, buscaram conhecer cada vez mais a natureza das pessoas sobre as quais elas devem agir (Rose, 2011), definindoas biologicamente, demograficamente e, por fim, a partir do campo econômico em que habitam e vivem (Avelino, 2016).

Com essa articulação entre enunciados científicos e econômicos, notase como o M21, a partir de sua plataforma digital, busca mobilizar os sujeitos para aderir ao programa. Dessa forma, o M21 acaba por atuar aliando elementos da racionalidade (neo)liberal e dos dispositivos biopolíticos como forma de governo das populações e de educação dos corpos na atualidade. A respeito da seção "Alguns dados que chamam atenção”, percebe-se que os dados ali presentes acabam por cumprir uma função de alerta às pessoas, visto que são informações que tratam de comportamentos como questões de vida e morte a partir da ênfase nos fatores de risco. Assim como nos conselhos presentes nos textos dos desafios do M21, os dados trazidos acima parecem confluir para a necessidade de os indivíduos investirem cada vez mais em si mesmos. A ênfase sobre o conceito de risco utilizado no programa acaba refletindo o quanto esse tem sido mobilizado pela sociedade contemporânea, chegando a se constituir em um dispositivo capaz de produzir demandas, discursos, linguagens e políticas. Para Mitjavila (2002, p. 135) "isto obedece, em grande parte ao fato de que o risco passa a exercer novas funções sociais, ao ponto de se converter em um dispositivo biopolítico central da vida social contemporânea”.

De acordo com a análise de Avelino (2016), Foucault discute que a biopolítica seria o que existe de mais específico na racionalidade liberal. Contudo, segue o autor, no regime liberal a biopolítica produz mais efeitos quando associada e justaposta àquilo denominado por Foucault de "poder pastoral”, ou seja, um tipo de poder mais individual e que investe nas subjetividades dos indivíduos para constituílos como sujeitos governáveis. Na próxima seção deste texto, apresentaremos a hipótese do poder pastoral presente nos enunciados do M21.

\section{Conduzindo sujeitos governáveis "por uma vida mais saudável"}

Se os enunciados do M21 e as falas de gestores da área da saúde nos deram pistas para analisarmos 
esse programa enquanto dispositivo biopolítico na atualidade, em outros espaços do site pudemos localizar elementos que nos permitem pensar na hipótese de o M21 usar de técnicas que remontam, em partes, à noção de poder pastoral.

Ao realizarmos o estudo da governamentalidade, chegamos às artes de governar, entre as quais encontramos o estudo do governo de si, o governo dos outros e as relações entre os dois governos (Castro, 2007). A biopolítica e o poder pastoral estão incluídos nesses campos de estudo e análise. Segundo Foucault (2008c), a racionalidade política começou a se desenvolver com a ideia do poder pastoral para depois chegar à razão de Estado:

Ao que me refiro na realidade é ao desenvolvimento das técnicas de poder orientadas aos indivíduos e destinadas a governalos de maneira contínua e permanente. Se o Estado é a forma política de um poder centralizado e centralizador, chamemos pastoral o poder individualizador. (Foucault, 2008c, p. 98)

O poder pastoral constituiu-se como uma das formas de intervenção sobre os sujeitos e seus modos de vida, tendo como intenção induzir as condutas individuais de cada pessoa, sem, contudo, necessitar do uso de ferramentas que demandem demasiadamente do Estado e de outras instituições. De acordo com a teoria foucaultiana, para que esse objetivo fosse alcançado, o poder pastoral passaria a lançar mão de tecnologias “de produção de verdades: ele ensina a verdade, a moral e os mandamentos. Assim ele é mestre em vários sentidos da verdade: por um lado a propaga e, por outro, deve saber tudo o que fazem os indivíduos que são suas ovelhas" (Paniago; Lima, 2014, p. 181).

Com os desafios da alimentação saudável, da prática de atividades físicas e do convívio familiar, o M21 busca ensinar, dar dicas de condutas a serem incorporadas no dia a dia das pessoas, de maneira a conduzilas por um caminho em vez de outros possíveis. Não há espaço para discussão dos desafios, há apenas aquilo que a equipe gestora do programa - amparada em determinados enunciados científicos e econômicos - acredita ser o melhor em termos de hábitos de vida para sua população. Desse modo, sujeitos são posicionados como responsáveis por suas escolhas, enquanto empreendedores de si mesmos, como se fossem capazes de adotar as mudanças no estilo de vida por 21 dias seguidos independentemente de suas condições de trabalho, moradia, renda, deslocamento, educação etc.

Para fazer isso, o site traz uma linguagem simples e acessível, centrando-se nos sujeitos e mostrando a eles como podem realizar as atividades propostas, valendo-se de recursos textuais, imagéticos, de peças publicitárias, de propagandas - como aquelas em que uma família relata sua nova rotina de vida após ter aderido aos desafios do programa. Há também um ranking dos usuários cadastrados no programa, de modo a estimular competição "saudável” para que as pessoas cumpram cada vez mais desafios. Vejamos trechos retirados do site do M21 que nos permitem pensar a respeito disso:

O Movimento 21 Dias por uma vida mais saudável é para ajudar você a mudar de hábitos. Mas é o seu empenho, foco e força de vontade que vão render os resultados. Por isso, não desista.

Convide uma pessoa para participar com você. Pode ser alguém da família, um amigo, ou alguém do trabalho. Assim, um apoia o outro, ao mesmo tempo em que gera uma disputa saudável. (Sobre..., 2015)

O estímulo à essa "disputa saudável" pode ser considerado uma das técnicas pensadas para manter um certo controle sobre os indivíduos, assim como uma forma de conhecê-los melhor, saber quais desafios estão escolhendo, quais estão conseguindo cumprir etc. Com o uso do aplicativo e do cadastro de emails, os sujeitos "aceitam", de certa forma, ter sua vida minimamente acessada pelo M21, que envia mensagens de encorajamento, de dúvidas, de incentivo, entre outras.

Nesse caso, diante de um contexto balizado pela racionalidade liberal, Estado e empresas privadas têm apostado cada vez mais na produção de aplicativos para celulares como mais uma ferramenta pedagógica (e mais econômica) para a educação dos corpos e a produção de subjetividades na atualidade (Fotopoulou; O’Riordan, 2016; Lupton, 2012; Rich; Miah, 2014). 
Os conselhos não estão mais localizados somente nos consultórios, igrejas e academias, pois agora eles estão em um aplicativo de celular que acompanha o sujeito no dia a dia e que ainda solicita ser acompanhado. A cada dia, a cada desafio cumprido ou não, os usuários devem informar o M21 por meio do aplicativo ou do site do programa. Além disso, o programa disponibiliza cartazes para que os sujeitos possam imprimir e colar em seus locais de moradia e trabalho, tornando-se, assim, multiplicadores do M21. Em evento de divulgação do PVS e do M21, um dos membros da equipe da Sesa do Espírito Santo ressalta essa necessidade de engajar diferentes setores da sociedade para disseminar o ideário desses programas:

O Vida Saudável é uma proposta que pode nos ajudar a viver mais e com mais qualidade. Entendendo que o Rotary é uma instituição com forte responsabilidade social, contamos que vocês possam encontrar formas de se comprometer e nos ajudar com essa iniciativa. (Membros..., 2015)

A partir desse exemplo, podemos perceber que o programa não só incentiva o autogoverno como também o governo dos outros (colegas, vizinhos, funcionários, sócios etc.). Tal lógica também entra em consonância com a racionalidade (neo)liberal, tornando cada um ao mesmo tempo réu e juiz, ovelha e pastor, em que "cada um é, simultaneamente, alvo (das múltiplas interpelações) e experto (supostamente sabedor do que lhe convém)" (VeigaNeto, 2000, p. 202).

Contudo, de maneira um pouco diferente do pastor do século XV e XVI descrito por Foucault, na atualidade a tarefa pastoral apresentase de uma outra maneira. Segundo Silvia Grinberg (2011), o pastor já não conduz seu rebanho para algum lado, mas o orienta para processos de autorregulação e autocondução. Com isso, o M21 em sua forma pastoral utiliza-se das plataformas digitais para tentar incentivar seu "rebanho" rumo ao autocontrole, ao autocuidado, visando a tomada de escolhas por um estilo de vida que julga ser o mais interessante, seja para a qualidade de vida, para a economia, para o trabalho ou para a saúde. Nikolas Rose (2007 apud Grinberg, 2011) argumenta que na contemporaneidade não estamos mais diante de um poder pastoral no qual o pastor conduz e dirige sujeitos confusos e indecisos, mas sim de um pastor do sintoma, do risco, que, para incidir sobre os sujeitos governáveis, adota princípios como o consentimento informado, a ação voluntária, a escolha individual e a ação não diretiva.

Podemos perceber a presença dos referidos princípios no caso do M21. A população capixaba não foi obrigada a se cadastrar no site ou a baixar o aplicativo: ela foi convidada. Os usuários cadastrados podem escolher os desafios que quiserem, mas devem se responsabilizar também pelo seu cumprimento em 21 dias. Não há compensação ou punição para aqueles que conseguirem ou não completar os 21 dias de um hábito. Contudo, pode existir a produção do sentimento de culpa, da sensação de fracasso e de competição entre os indivíduos cadastrados.

Nesse tipo de estratégia não diretiva, nota-se que o controle e o governamento ocorrem de maneira mais sutil, tanto de forma individual quanto massificada. A intenção do pastor contemporâneo deixa de ser a de centralizar todas as ações para ser a de instigar, por meio da figura do especialista, do conselheiro, a produção de sujeitos governáveis e a formação de um rebanho de mais pastores, que passam a vigiar a si mesmos e aos outros (Pich, 2016).

Diante desse cenário em que "o neoliberalismo forneceu ao poder político uma racionalidade governamental que permitiu integrar à economia um amplo conjunto de técnicas comportamentais" (Avelino, 2016, p. 276), permitindo a articulação entre os princípios da economia e o extenso campo de práticas de indução das condutas - no qual as campanhas de promoção e educação em saúde (como o M21) se tornaram um espaço de atuação e intervenção calculista, atuarial e "a distância" sobre os sujeitos -, o poder pastoral quando associado à biopolítica tende a produzir mais efeitos sobre o investimento nas subjetividades dos indivíduos para constituílos como sujeitos governáveis. Tais práticas têm demonstrado uma aproximação com a racionalidade liberal, agindo sobre os indivíduos de maneira menos intervencionista, mas sem perder de alcance a disciplina, o controle e a normalização da população, valendo-se dos discursos do risco, da economia, do autocuidado e do empreendedorismo de si mesmo (Lupton, 2000; Rose, 2011). 
Os desafios enunciados pelo M21 constituemse como orientações e conselhos racionais em vez de ordens. Porém, isso não minimiza o fato de que os mesmos enunciados posicionam os sujeitos como principais responsáveis pelo cumprimento dos desafios. Luciana Caliman (2015, p. 306) coloca que esse tipo de estratégia se tornou um dos aspectos centrais da nova racionalidade de governo, exigindo um trabalho contínuo e permanente para tornar viável sua preservação e reconstrução, enquanto a noção de "indivíduo como gestor de si passa a ser fortalecida como premissa básica da vida contemporânea”. Entretanto, como afirma a autora, sabe-se "que a responsabilidade individual pela escolha e pela manutenção da vida e dos meios necessários para tornar este trabalho possível não são igualmente distribuídos" (Caliman, 2015, p. 306307).

Deborah Lupton (200o) é outra autora que alerta para o fato de que as práticas realizadas em nome da promoção da saúde que visam a adoção de estilos de vida saudáveis por meio da condução de condutas acabam contendo caráter individualista, que apenas transfere a responsabilidade para os indivíduos, e têm privilegiado determinado tipo de corpo, determinado tipo de sujeito, capaz de se autorregular, pertencendo às classes média e alta, tendo renda e moradia razoáveis e, com isso, mais chances de acessar o estilo de vida saudável propagado.

Cabe perguntar se os desafios propostos pelo M21 não estariam dentro dessa perspectiva dos programas de promoção da saúde salientada pela autora, visto que nos enunciados das plataformas digitais do M21 há uma pacificação, naturalização e generalização das ações, como se qualquer pessoa tivesse as condições necessárias para adotar os hábitos sugeridos. Em nossa análise, uma parcela dos desafios propostos pelo programa não parece viável para todas as pessoas praticarem por 21 dias seguidos ${ }^{8}$ (pelo menos da forma como o site tenta induzir), se considerarmos os conflitos, as tensões, os trabalhos, as desigualdades socioeconômicas, as diferentes formas de constituição de famílias e a diversidade cultural presentes no cotidiano da população.
Enquanto condutor de condutas possíveis de serem autogeridas por indivíduos governáveis, o M21 em sua faceta pastoral mobiliza enunciados e técnicas de supervisão e controle para alcançar certa economia e eficiência, forjando, assim, uma relação entre as formas pelas quais somos governados pelos outros e as formas pelas quais deveríamos nos governar (Rose, 2011) em torno de um projeto por uma vida mais saudável.

\section{Considerações finais}

$\varepsilon$ de onde esses sabichões tiraram que o homem necessita não sei de que vontade normal, virtuosa? De onde partiu essa sua ideia de que o homem precisa ter obrigatoriamente uma vontade sensatamente vantajosa? O que o homem precisa é somente de uma vontade independente, custe ela o que custar e não importa aonde possa conduzir

Dostoiévski, 2016

Parecenos que, a partir da leitura e da análise dos conteúdos expostos no site do M21, o programa atua como mais uma das estratégias do campo da saúde associada ao biopoder na contemporaneidade (Castiel; Moraes; Paula, 2016; Ferreira Neto et al., 2009), acionando estratégias biopolíticas, pautando o corpo da população em números e dados e traduzindo os riscos e benefícios de se adotar determinado estilo de vida, buscando produzir nos sujeitos a necessidade pela busca daquilo que o personagem de Dostoiévski chamou de "vontade virtuosa, da vontade sensatamente vantajosa”. Os enunciados, ao mesmo tempo que parecem não obrigar ninguém a praticar os desafios, possuem também uma carga alta de responsabilização dos indivíduos, jogando com um espectro da culpa pessoal, seja por não aderir ao programa ou por não conseguir atingir a meta dos 21 dias de algum desafio etc.

Sendo assim, como em outras políticas sobre o corpo, o M21 acaba por abarcar um dos elementos principais da biopolítica atual: o de tentar intervir no "como" da vida, "isto é, na maneira como as pessoas

8 Desafios como: reduzir consumo de alimentos com carboidratos simples (arroz, batata, biscoito), comer cinco cores ao dia, comer de 3 em 3 horas, inserir grãos integrais na alimentação; pular corda por 20 minutos, andar de bicicleta por 30 minutos, praticar um esporte; reunir a família à mesa nas refeições, fazer atividades externas em família. 
devem viver, cuidar de si, para assim buscarem aumentar sua expectativa de vida e controlar seus riscos" (Furtado; Szapiro, 2012, p. 819). Tal tipo de intervenção, que instiga os sujeitos a se responsabilizar cada vez mais com seus modos e hábitos de vida, apresenta-se, não por acaso, em um cenário repleto de narrativas sobre crise econômica e a necessidade de aplicação de medidas de austeridade como forma de frear os problemas financeiros e, consequentemente, diminuir a intervenção do Estado e os investimentos nas políticas sociais. A partir desses elementos, pode-se dizer que no âmbito da proteção social, os programas neoliberais contemporâneos tendem a priorizar cada vez mais as estratégias para privatização, individualização e contratualização de políticas sociais residuais, como já pode ser visto em áreas como saúde, lazer, educação e segurança.

Quanto às formas de governamento dos sujeitos e da educação dos corpos na contemporaneidade, a análise do M21 permitiu-nos pensar em como os dispositivos biopolíticos têm buscado incidir sobre as vidas das pessoas, agora com o adendo da tecnologia como propulsora de informações, conselhos e ideias capazes não só de atuar de forma sutil, mas também de acompanhar a população de maneira mais constante.

Por fim, sugerimos para futuros estudos a análise e o acompanhamento de usuários de programas como o M21, para melhor entender como eles recebem esses tipos de informação e de que formas as utilizam em seus cotidianos; ou, ainda, o quanto - e em que medida - se valem da vontade virtuosa e da vontade independente, sendo esta última a proposta de Dostoiévski para uma possibilidade de linha de fuga, de resistência e de criação de fissuras no muro rígido da normalização da vida.

\section{Referências}

AVELINO, N. Foucault e a racionalidade (neo)liberal. Revista Brasileira de Ciência Política, Brasília, DF, n. 1, p. 227-284, 2016. Disponível em: <http://bit. ly/3oBIard $>$. Acesso em: 26 ago. 2019.

ÁVILA, L. M. A produção do conhecimento sobre estratégias de promoção da saúde. $\varepsilon$ cos, Rio de Janeiro, v. 4, n. 2, p. 201-212, 2014. Disponível em: <http://bit.ly/2ZqH4RT>. Acesso em: 26 ago. 2019.
BAUMAN, Z. Vidas desperdiçadas. Rio de Janeiro: Zahar, 2005.

BAZZICALUPO, L. L'economia come logica di governo. Spazio Filosofico, Turim, n. 7, p. 21-29, 2013. Disponível em: <https://bit.ly/2Zmo1Wt>. Acesso em: 26 ago. 2019.

BILIBIO, L. F.; DAMICO, J. G. S. Carta a um jovem professor. Cadernos de Formação RBCE, Florianópolis, v. 2, n. 2, p. 92-103, 2011. Disponível em: <http://bit.ly/2zoorPS>. Acesso em: 26 ago. 2019.

CALIMAN, L. Quando os estilos de vida se tornam estilos de risco. In: BAGRICHEVSKY, M.; ESTEVÃO, A. (Org.). Saúde coletiva: dialogando sobre interfaces temáticas. Ilhéus: Editus, 2015. p. 291-318.

CARDOSO, I. A. R. Foucault e a noção de acontecimento. Tempo Social, São Paulo, v. 7 , n. 1-2, p. 53-66, 1995. Disponível em: <http://bit. ly/2PdYcGA>. Acesso em: 26 ago. 2019.

CASTEL, R. La inseguridad social: ¿qué es estar protegido? Buenos Aires: Manantial, 2004.

CASTIEL, L. D.; MORAES, D. R.; PAULA, I. J.

Terapeuticalização e os dilemas preemptivistas na esfera da saúde pública individualizada. Saúde e Sociedade, São Paulo, v. 25, n. 1, p. 96-107, 2016. Disponível em: <http://bit.ly/2KVTdWL >. Acesso em: 26 ago. 2019.

CASTRO, E. Biopolítica y gubernamentalidad. Temas \& Matizes, Maringá, v. 1, n. 11, p. 8-18, 2007. Disponível em: <http://bit.ly/2Pad8oX>. Acesso em: 26 ago. 2019.

CASTRO, E. Biopolítica: orígenes y derivas de un concepto. Cuadernos de Trabajo: Biopolítica: Gubernamentalidad, Educación, Seguridad, La Plata, v. 1, n. 1, p. 5-12, 2011. Disponível em: <http://bit.ly/2ZcQ65w>. Acesso em: 26 ago. 2019. COSTA, R. Políticas da vida e pedagogias do corpo. In: GOMES, I. M.; FRAGA, A. B.; CARVALHO, Y. M. (Org.). Práticas corporais no campo da saúde 3. São Paulo: Hucitec, 2016. p. 23-41. (Interlocuções: Práticas, Experiências e Pesquisas em Saúde).

DOSTOIÉVSKI, F. Notas do subsolo. Porto Alegre: L\&PM, 2016. 
FERREIRA NETO, J. L. et al. Apontamentos sobre promoção da saúde e biopoder. Saúde e Sociedade, São Paulo, v. 18, n. 3, p. 456-466, 2009. Disponível em: <http://bit.ly/2ZiK7MD>. Acesso em: 26 ago. 2019.

FOTOPOULOU, A.; O'RIORDAN, K. Training to self-care: fitness tracking, biopedagogy and the healthy consumer. Health Sociology Review, Abingdon, v. 26, n. 1, p. 54-68, 2016.

FOUCAULT, M. Microfísica do poder. Rio de Janeiro: Graal, 2000.

FOUCAULT, M. Em defesa da sociedade. São Paulo: Martins Fontes, 2005.

FOUCAULT, M. Ética, sexualidade, política. Rio de Janeiro: Forense Universitária, 2006. (Ditos \& Escritos, 5).

FOUCAULT, M. Nascimento da biopolítica. São Paulo: Martins Fontes, 2008a.

FOUCAULT, M. Segurança, território, população. São Paulo: Martins Fontes, 20o8b.

FOUCAULT, M. Tecnologías del yo. Buenos Aires: Paidós, 2008c.

FRAGA, A. B. Exercício da informação: governo dos corpos no mercado da vida ativa. 2005. Tese (Doutorado em Educação) - Universidade Federal do Rio Grande do Sul, Porto Alegre, 2005.

FURTADO, M.; SZAPIRO, A. Promoção da saúde e seu alcance biopolítico: o discurso sanitário da sociedade contemporânea. Saúde e Sociedade, São Paulo, v. 21, n. 4, p. 811-821, 2012. Disponível em: <http://bit.ly/31WDmwW >. Acesso em: 26 ago. 2019.

GOMES, I. M. Conselheiros modernos: propostas para a educação do indivíduo saudável. 2008. Tese (Doutorado em Ciências Humanas) - Universidade Federal de Santa Catarina, Florianópolis, 2008.

GOVERNO do Estado lança Programa Vida Saudável. Movimento 21 dias por uma vida mais saudável, Vitória, 26 jan. 2016. Disponível em: <http://bit.ly/2ZtEwhA>. Acesso em: 26 ago. 2019. GRINBERG, S. La conjetura del ADN. Cuadernos de Trabajo: Biopolítica: Gubernamentalidad, Educación, Seguridad, La Plata, v. 1, n. 1, p.13-24,
2011. Disponível em: <http://bit.ly/2ZcQ65w>. Acesso em: 26 ago. 2019.

LUPTON, D. Corpos, prazeres e práticas do eu. Educação \& Realidade, Porto Alegre, v. 25, n. 2, p. 45-58, 200o. Disponível em: <http://bit. ly/2KUdFHy>. Acesso em: 26 ago. 2019.

LUPTON, D. M-health and health promotion: the digital cyborg and surveillance society. Social Theory e Health, Nova York, v. 10, n. 3, p. 229-244, 2012. Disponível em: <http://bit.ly/2Zw4FR4>. Acesso em: 26 ago. 2019.

MÁZARO, L. P.; BERNARDES, A. G.; COÊLHO, A. E. L. Análise das políticas públicas de prevenção e promoção em saúde sob um olhar foucaultiano. Revista Polis e Psique, Porto Alegre, v. 1, n. 1, p. 130-148, 2011. Disponível em: <http://bit. ly/2HpaXHU>. Acesso em: 26 ago. 2019.

MEMBROS do Rotary Club conhecem Programa Vida Saudável. Movimento 21 dias por uma vida mais saudável, Vitória, 10 dez. 2015. Disponível em: <http://bit.ly/2MEJciW>. Acesso em: 10 set. 2016.

MITJAVILA, M. O risco como recurso para a arbitragem social. Tempo Social, São Paulo, v. 14, n. 2, p. 129-145, 2002. Disponível em: <http://bit. ly/2HrgMVk>. Acesso em: 26 ago. 2019.

MUNIZ, A. Combate ao Aedes aegypti ganha mais um aliado. Movimento 21 dias por uma vida mais saudável, Vitória, 19 fev. 2016. Disponível em: <http://bit.ly/2HryJmG>. Acesso em: 10 set. 2016.

PANIAGO, M.; LIMA, P. A. Poder pastoral em Men's Health: forjando tipos femininos para fabricar identidades masculinas. Revista (Con) Textos Linguísticos, Vitória, v. 8, n. 10, p. 175-194, 2014. Disponível em: 〈http://bit.ly/2U9vvc0〉. Acesso em: 26 ago. 2019.

PASSETTI, E. Transformações da biopolítica e emergência da ecopolítica. Ecopolítica, São Paulo, n. 5, p. 2-37, jan./abr. 2013. Disponível em: <http:// bit.ly/2MCEguV>. Acesso em: 26 ago. 2019.

PICH, S. Saberes do/sobre o corpo: governamentalidade, biopolítica e cuidado de si. In: GOMES, I. M.; FRAGA, A. B.; CARVALHO, Y. M. (Org.). Práticas corporais no campo da saúde 3. 
São Paulo: Hucitec, 2016. p. 154-171. (Interlocuções: Práticas, Experiências e Pesquisas em Saúde).

RABINOW, P.; ROSE, N. O conceito de biopoder hoje. Política e Trabalho, João Pessoa, n. 24, p. 27-57, abr. 20o6. Disponível em: <http://bit. ly/2NypNjp>. Acesso em: 26 ago. 2019.

RICH, E.; MIAH, A. Understanding digital health as public pedagogy: a critical framework. Societies, Basileia, v. 4, n. 2, p. 296-315, 2014. Disponível em: <http://bit.ly/2KWLp7j>. Acesso em: 26 ago. 2019.

RODRIGUES, J. Governo do Estado lança Programa Vida Saudável. Sesa, Vitória, 19 out. 2015. Disponível em: 〈http://bit.ly/2NvfPzo>. Acesso em: 26 ago. 2019.

ROSE, N. Inventando nossos selfs: psicologia, poder e subjetividade. Petrópolis: Vozes, 2011.
ROSE, N. A política da própria vida: biomedicina, poder e subjetividade no século XXI. São Paulo: Paulus, 2013.

SOBRE o Movimento. Movimento 21 dias por uma vida mais saudável, Vitória, 16 out. 2015. Disponível em: <http://bit.ly/2ZkkGKu>. Acesso em: 26 ago. 2019.

STUTZ, A. C. Movimento 21 Dias: mais de 19.500 cadastros em quatro meses. Governo $E S$, Vitória, 16 fev. 2016. Disponível em: <http://bit. ly/2ZiRBzo>. Acesso em: 26 ago. 2019.

VEIGA-NETO, A. J. Educação e governamentalidade neoliberal: novos dispositivos, novas subjetividades. In: PORTOCARRERO, V.; BRANCO, G. C. (Org.).

Retratos de Foucault. Rio de Janeiro: Nau, 2000. p. 179-217.

\section{Contribuição dos autores}

Abib realizou a pesquisa de campo. Gomes orientou o trabalho e revisou o manuscrito. Ambos os autores analisaram os dados $e$ redigiram o artigo.

Recebido: 19/02/2019

Reapresentado: 24/07/2019

Aprovado: 10/08/2019 